\title{
Cytoarchitectonic Areas of the Gyrus ambiens in the Human Brain
}

\section{Ricardo Insausti ${ }^{1 *+}$, Marta Córcoles-Parada ${ }^{1 \dagger}$, Mar Maria Ubero ${ }^{2}$, Adriana Rodado Ana Maria Insausti ${ }^{3}$ and Mónica Muñoz-López'}

\begin{abstract}
${ }^{1}$ Human Neuroanatomy Laboratory, School of Medicine, University of Castilla-La Mancha, Albacete, Spain, ${ }^{2}$ Departamento de Anatomía, Universidad Católica San Antonio de Murcia, Murcia, Spain, ${ }^{3}$ Faculty of Health Sciences, University Public of Navarra, Pamplona, Spain
\end{abstract}

The Gyrus ambiens is a gross anatomical prominence in the medial temporal lobe (MTL), associated closely with Brodmann area 34 (BA34). It is formed largely by the medial intermediate subfield of the entorhinal cortex (EC) [Brodmann area 28 (BA28)]. Although the MTL has been widely studied due to its well-known role on memory and spatial information, the anatomical relationship between G. ambiens, BA34, and medial intermediate EC subfield has not been completely defined, in particular whether BA34

OPEN ACCESS

Edited by:

Hans J. ten Donkelaar Radboud University Nijmegen, Netherlands

Reviewed by: Menno P. Witter

Norwegian University of Science and Technology, Norway Loreta Medina

Universitat de Lleida, Spain

*Correspondence:

Ricardo Insausti

ricardo.insausti@uclm.es

†These authors have contributed equally to this work

Received: 23 September 2018 Accepted: 05 February 2019

Published: 21 February 2019

Citation:

Insausti R, Córcoles-Parada M Ubero MM, Rodado A, Insausti AM and Muñoz-López M (2019) Cytoarchitectonic Areas of the Gyrus ambiens in the Human Brain.

Front. Neuroanat. 13:21. doi: 10.3389/fnana.2019.00021 is part of the EC or a different type of cortex. In order to clarify this issue, we carried out a detailed analysis of 37 human MTLs, determining the exact location of medial intermediate EC subfield and its extent within the G. ambiens, its cortical thickness, and the histological-MRI correspondence of the $G$. ambiens with the medial intermediate EC subfield in 10 ex vivo MRI. Our results show that the $G$. ambiens is limited between two small sulci in the medial aspect of the MTL, which correspond almost perfectly to the extent of the medial intermediate EC subfield, although the rostral and caudal extensions of the G. ambiens may extend to the olfactory (rostrally) and intermediate (caudally) entorhinal subfields. Moreover, the cortical thickness averaged $2.5 \mathrm{~mm}(1.3 \mathrm{~mm}$ for layers I-III and $1 \mathrm{~mm}$ for layers $\mathrm{V}-\mathrm{VI})$. Moreover, distance among different landmarks visible in the MRI scans which are relevant to the identification of the G. ambiens in MRI are provided. These results suggest that BA34 is a part of the EC that fits best with the medial intermediate subfield. The histological data, together with the ex vivo MRI identification and thickness of these structures may be of use when assessing changes in MRI scans in clinical settings, such as Alzheimer disease.

Keywords: human, entorhinal cortex, subfield EMI, ambient gyrus, cytoarchitectonics, BA34

Abbreviations: BA, Brodmann area; BA35, Brodmann area 35 or perirhinal cortex; BA36, Brodmann area 36 or entorhinal cortex; $\mathrm{EC}$, entorhinal cortex; $\mathrm{E}_{\mathrm{C}}$, caudal subfield of the entorhinal cortex; $\mathrm{E}_{\mathrm{CL}}$, caudal limiting subfield of the entorhinal cortex; $\mathrm{E}_{\mathrm{I}}$, intermediate subfield of the entorhinal cortex; $\mathrm{E}_{\mathrm{LC}}$, lateral caudal subfield of the entorhinal cortex; $\mathrm{E}_{\mathrm{LR}}$, lateral rostral subfield of the entorhinal cortex; $\mathrm{E}_{\mathrm{MI}}$, medial intermediate subfield of the entorhinal cortex; $\mathrm{E}_{\mathrm{O}}$, olfactory subfield of the entorhinal cortex; $\mathrm{E}_{\mathrm{R}}$, rostral subfield of the entorhinal cortex; GA, Gyrus ambiens; GS, Gyrus semilunaris; GU, Gyrus uncinatus; MTL, medial temporal lobe; PHG, parahippocampal gyrus. 


\section{INTRODUCTION}

The entorhinal cortex (EC) or Cortex Entorhinalis ${ }^{1}$ is a component of the hippocampal formation (HF), which is formed by different archicortical (dentate gyrus, CA fields, subiculum) and periarchicortical areas (presubiculum, parasubiculum, EC). In humans, the EC forms part of the parahippocampal gyrus (PHG) or Gyrus parahippocampalis. The PHG is located in the ventromedial surface of the temporal lobe, which, with the adjacent cortex lining the collateral sulcus or sulcus collateralis, forms the medial temporal lobe (MTL).

The MTL has been associated to functions such as memory and processing of spatial information (Aggleton and Mishkin, 1985; Maguire et al., 2000; Squire et al., 2004). The vast majority of the information entering the nonhuman primate EC comes exclusively from polysensory association areas (for review, see Insausti et al., 2017). The majority of the cortical input reaches the upper layers of EC subfields over the rostro-caudal and mediolateral extents of the EC (Suzuki and Amaral, 1994; Insausti and Amaral, 2008; Mohedano-Moriano et al., 2008). The cortical output leaves the EC through the deep layers (V and VI) and sends information back to polysensory areas that send input to EC (Muñoz and Insausti, 2005). Pathological processes in the EC are considered as one of the hallmarks of Alzheimer disease (Braak and Braak, 1992) with a decrease in neuron number occurs, not only in upper layers (Gómez-Isla et al., 1996), but also in deep layers as well (Arnold et al., 1991).

Along the years, the study of the MTL, and in particular in the field of Alzheimer disease, has also incorporated neuroimaging techniques which can determine both the location of the EC in MRI images (Insausti et al., 1998a), as well as its structural and volumetric changes (Juottonen et al., 1998; Khan et al., 2014).

The EC laminar structure is known since Hammarberg (1895) and can be found in classical neuroanatomical work (Cajal, 1901; Lorente de Nó, 1933), although it was not topographically described until Brodmann (1909). He divided the MTL into area 28 (EC), located in the anterior portion of the PHG, and area 34, which lies medial to area 28. BA34 corresponds approximately to the macroscopically visible ambient gyrus or Gyrus ambiens (GA). The GA forms in the human brain a visible protuberance situated in the medialmost portion of the anterior temporal lobe. This parcellation of the cerebral cortex is not completely accepted by contemporary authors who challenge the correspondence of Brodmann's cortical areas as defined by functional studies (Nieuwenhuys et al., 2015).

The GA as an anatomical structure is known since Solly (1836), who described it in relation to the limen insulae (Swanson, 2015). The GA was assigned first to the olfactory system and later included as part of the piriform area by Smith in 1919 (Swanson, 2015). Williams and Warwick (1980) include the GA as part of the prepiriform area, which continues caudally into the entorhinal area.

${ }^{1}$ Latin nomenclature, from Terminología Neuroanatómica (2017) FIPAT.library.dal.ca. Federative International Programme for Anatomical Terminology is mentioned in italics in the text, alongside the common English terms used in neuroanatomical literature (illustrated version in ten Donkelaar et al., 2018).
The GA (Figures 1A,B) is the largest and most outstanding gross macroscopic prominence of the PHG. Other bulge in the most anterior part of the MTL is the semilunar gyrus (GS), separated from the GA by the semianular sulcus or sulcus semianularis ${ }^{2}$. Cytoarchitectonically, the GS corresponds to periamygdaloid cortex (Insausti and Amaral, 2012). Another bulge close to the GA is uncinate gyrus (GU), which lies caudal to the GA and GS, at the transition between the caudalmost portion of the amygdala and the hippocampus (Figure 1B). Therefore, the GA can be considered as a medial extension of the PHG in the MTL.

As mentioned above, the cortex situated in the anterior part of the PHG is the EC, a phylogenetically conserved brain region present in all mammals (Stephan, 1975). The cytoarchitecture of the EC has been subject of study since the middle of the nineteenth century, and it has been subdivided into different subfields (Amaral et al., 1987; Insausti et al., 1995, and references therein). The best-known synonym of EC is BA28, and both are used in an interchangeable way. Somewhat less clear is the type of cortex present in BA34. Brodmann describes it as: "Area 34 - the dorsal entorhinal area. It lies mainly to the inferior rhinencephalic sulcus (Retzius, 1896), so that this sulcus forms the approximate border between both types" (Brodmann, 1909, translation of Garey, 1994). The other area alluded to is BA28 or EC. It is obvious that Brodmann only gives an account of the location of his dorsal entorhinal area, without any further elaboration on cytoarchitectonic characteristics.

Brodmann's gross anatomical drawing of the human cortical area shows that area 34 is largely coincident with the macroscopic GA. Moreover, Brodmann indicates the "inferior rhinencephalic sulcus" (Retzius, 1896) as the boundary between areas 28 and 34 and refers to the cortex of the "lunate gyrus" of Retzius (equivalent to GS) on the medial side of area 34 (Figure 1A). Therefore, Brodmann makes a clear distinction of two separate areas, area 28 or EC, and area 34 in the anterior part of the PHG. Area 34 is still in use by some authors (Krimer et al., 1997; Ding, 2013).

The gross anatomical organization of the MTL has been dealt with in several reports (Amaral and Insausti, 1990; Duvernoy, 2005; Insausti and Amaral, 2012), and they all agree with the commonly accepted pattern of the series of bulges present in the medialmost aspect of the MTL. However, the pattern of sulci present in the PHG is more controversial, and reports in the literature show a disparity of names (Heckers et al., 1990; Ono et al., 1990; Heinsen et al., 1996; Hanke, 1997; Duvernoy, 2005; Huntgeburth and Petrides, 2012). Finally, although the cytoarchitectonic segmentation of the human EC has been studied along the last century, some differences still persist (Insausti et al., 1995; Krimer et al., 1997).

Modern MRI techniques reveal the anatomy of the MTL in detail and great accuracy (Yushkevich et al., 2015; Iglesias et al., 2016), so that the shape and extension of the medial temporal bulges (GA, GS, and GU) can be readily assessed. Thereby, the anatomical identification of the medial temporal

${ }^{2}$ Usually cited in its Latin form, thereby we will continue using this form in the manuscript. 

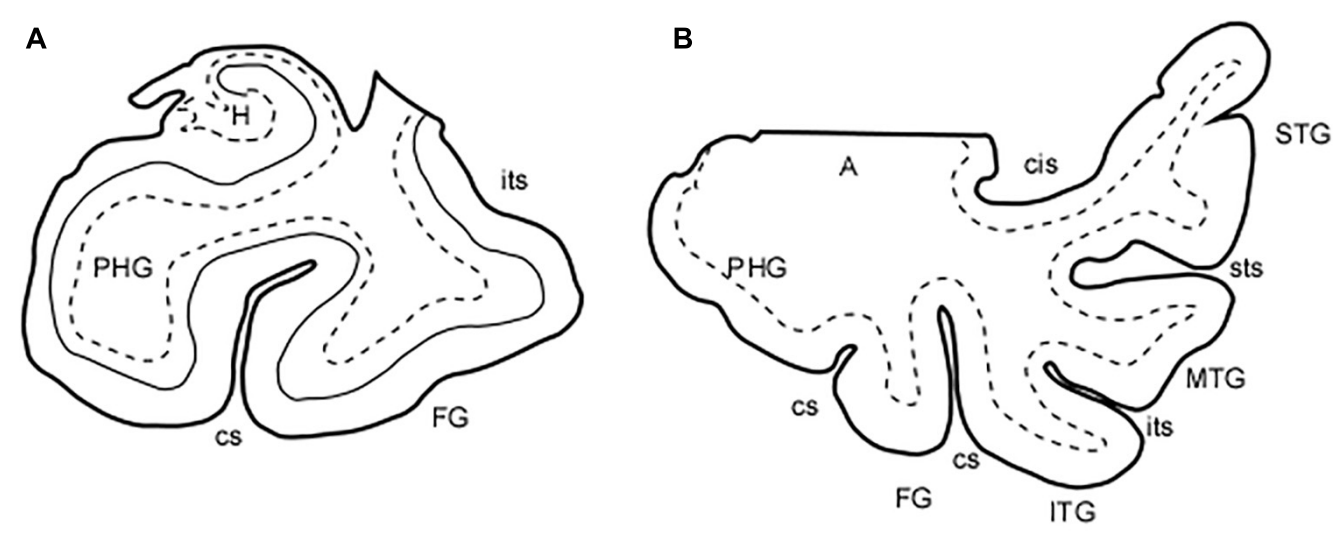

C

D
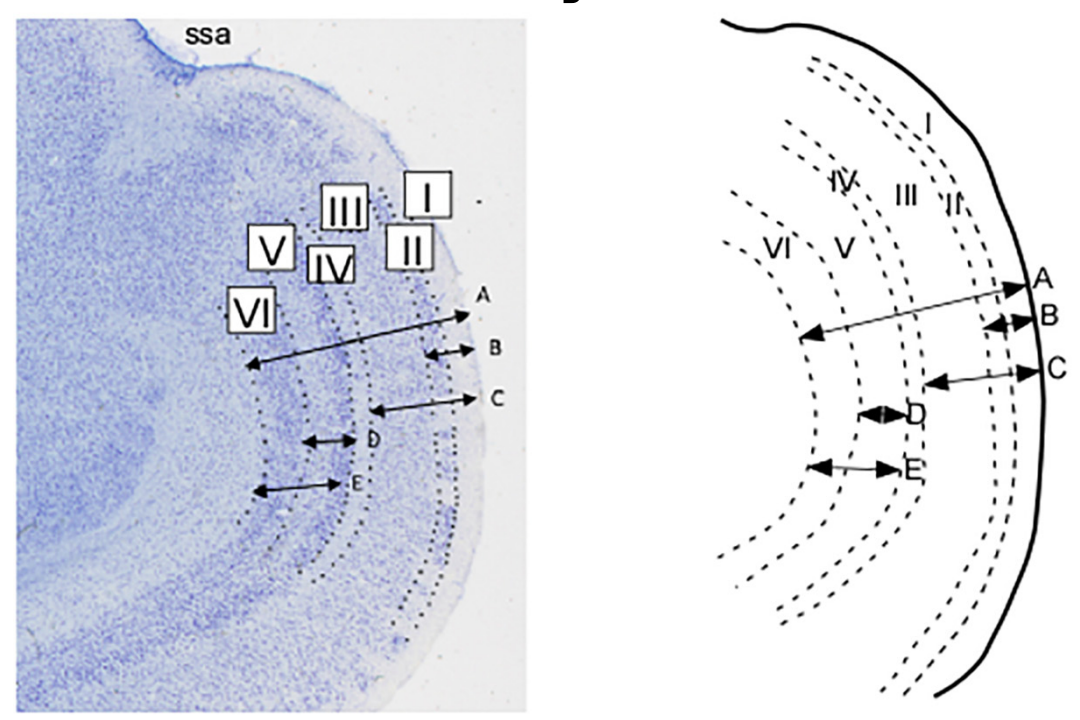

FIGURE 1 | Schematic representation of the extent of the blocks employed in this study. (A) Block limited to the parahippocampal and fusiform gyri. (B) Blocks of the whole temporal lobe as far as the circular sulcus of the insula. (C) Microphotograph in which the layers of the EC subfield $\mathrm{E}_{\mathrm{Ml}}$ can be appreciated. Arrows represent the measurements made of the total and partial thicknesses of the cortex in $E_{M l}$. These are represented schematically in (D) as indicated: $A$, total thickness of subfield $\mathrm{E}_{\mathrm{Ml}}$; B, thickness of layers I and II; C, thickness of layers I-III; D, thickness of layer V; E, thickness of layers V and VI. Abbreviations: A, amygdala; cs, collateral sulcus; FG, fusiform gyrus; H, hippocampus; ITG, inferior temporal gyrus; its, inferior temporal sulcus; MTG, middle temporal gyrus; PHG,

parahippocampal gyrus; ssa, sulcus semianularis; STG, superior temporal gyrus; sts, superior temporal sulcus.

prominences (Stephan, 1975; Amaral and Insausti, 1990; Duvernoy, 2005; Insausti and Amaral, 2012; Ding and Van Hoesen, 2015) makes it possible to use its morphometry in studies on neurodegenerative diseases, such as in Alzheimer disease.

The aim of this descriptive study is twofold. First, we sought to explore the detailed macroscopic anatomy of the GA, and its relationship with other bulges and sulci at the upper MTL, in order to check the feasibility of MRI identification of the GA in relation to other medial temporal landmarks. Second, we wanted to determine the cytoarchitectonic fields that conform the GA, both at the mediolateral and rostrocaudal extents, as our previous cytoarchitectonic parcellation of the human EC suggest that the GA may contain more than one EC subfield (Insausti et al., 1995).

\section{MATERIALS AND METHODS}

The study was performed according to the Declaration of Helsinki and approved by the Ethical Committee on Clinical Research of the University Hospital of Albacete (meeting of January 2015).

The results presented are based on observations of 37 MTLs of control cases, ranging between 12 and 110 years, from the Human Neuroanatomy Laboratory archive at the University of Navarra (1985-1998) and the University of Castilla-La Mancha (1999present). Most of them were fixed by immersion in $10 \%$ buffered formalin for at least 4 weeks. Brains were photographed and blocked in $1 \mathrm{~cm}$ thick slabs (coronal plane), either perpendicular to the line traced along the anterior and posterior commissures as previously used in other studies (Insausti et al., 1995), 
or taking the posterior end of both mammillary bodies as references.

The anterior and posterior surfaces of the slabs were individually photographed and the MTL was dissected through a medial cut along the entorhinal sulcus (Gloor, 1997) or posterior to the end of the Gyrus intralimbicus, at the most caudal level of the uncus, also known as the uncal apex by Duvernoy (2005), along the choroidal fissure (fissura choroidea). The block of tissue encompassed either the lateral occipitotemporal sulcus (sulcus occipitotemporalis lateralis) as presented in Figure 2A, or the most complete temporal lobe by the circular sulcus of the insula (sulcus circularis insulae) at the level of the insular cortex (Figure 2B). The dissected temporal lobe blocks included from the temporal pole and anterior PHG to the end of the hippocampus and associated cortices at the beginning of the lingual gyrus (Gyrus lingualis).
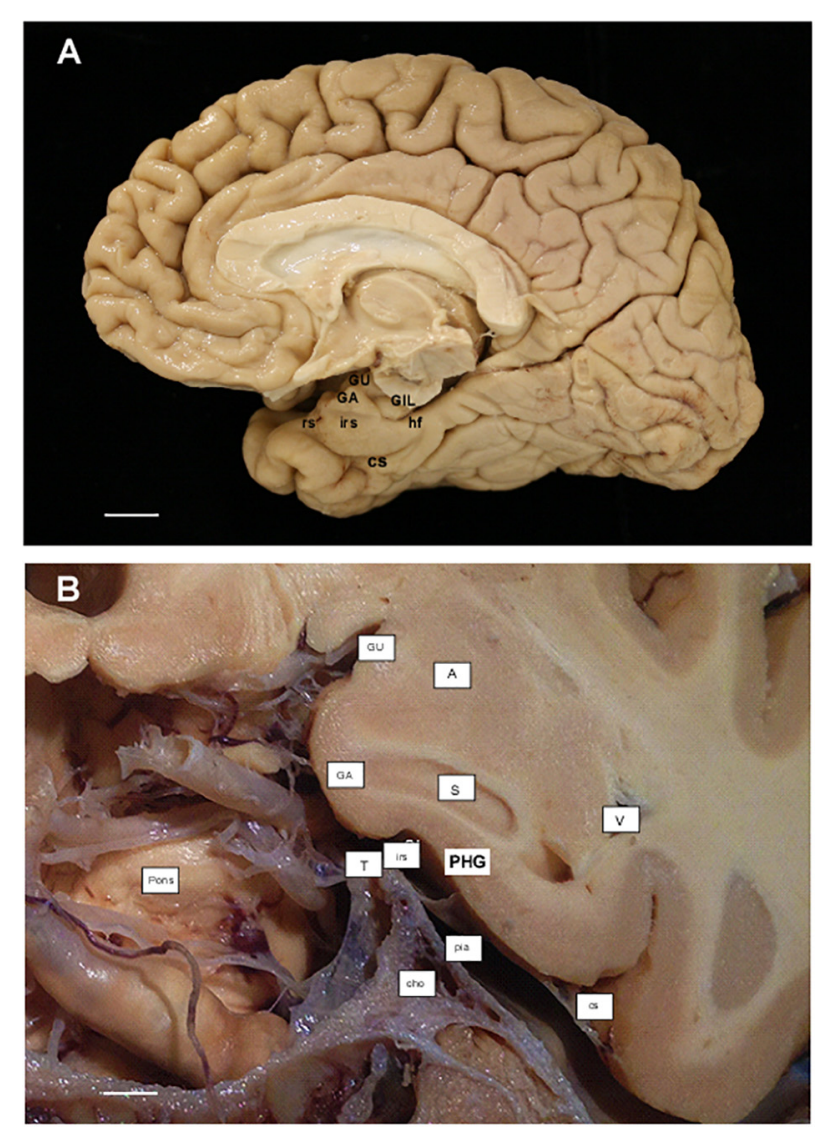

FIGURE 2 | (A) Photograph of the medial aspect of a cerebral hemisphere showing the main gross anatomical structures in relation to the remainder of cerebral structures. Scale bar equals $1 \mathrm{~cm}$. (B) Photograph of a cadaveric preparation of a coronal section of the head at the level of the Subiculum (start of the hippocampus). Notice the ventral limit of the intrarhinal sulcus in relation to the G. ambiens (GA). The free edge of the tentorium (T) can be appreciated in close proximity to the intrarhinal sulcus. Scale bar equals $5 \mathrm{~mm}$. Abbreviations as in previous Figure 1: cho, anterior choroidal artery; GA, Gyrus ambiens; GIL, Gyrus intralimbicus; GU, Gyrus uncinatus; hf, hippocampal fissure; irs, intrarhinal sulcus; pia, pia mater; Pons, anterior aspect of the pons; rs, rhinal sulcus; S, subiculum; T, tentorium; V, lateral ventricle, temporal horn.
The dissected blocks were placed in $4 \%$ paraformaldehyde in $0.1 \mathrm{M}$ phosphate buffer for a period of 2-4 weeks. Serial $50 \mu \mathrm{m}$ thickness sections were obtained with the use of a sliding microtome coupled to a freezing unit as described previously (Insausti et al., 1995; Blaizot et al., 2010). One-in-ten sections were Nissl stained with $0.25 \%$ thionin for cytoarchitectonic evaluation (500 $\mu \mathrm{m}$ interval between adjacent sections).

Annotation of boundaries was made by means of a camera lucida attached to a Nikon SMZ or a Leica MZ6 stereomicroscope. In all cases, a thorough analysis of the cytoarchitectonic features was made on the basis of previously reported criteria for the EC (Insausti et al., 1995), perirhinal cortex $^{3}$ (Salinas, 1995), and posterior parahippocampal cortex ${ }^{4}$ (Insausti, 1992). Sections throughout the GA were selected for estimation of total thickness, as well as that of its layers (Figure 2).

In each case the linear distance between the pia mater and the boundary with the white matter was measured, along with different combinations of layers and cell free spaces up to five length determinations: (1) total thickness of EC subfield $\mathrm{E}_{\mathrm{MI}}$ taken at the most convex point of the GA; (2) thickness of layer I plus layer II, which estimates the value of the layer origin of the projection to the molecular layer of the dentate gyrus; (3) thickness of the sum of layers I, II, and III as an estimate of the layers that project both to the CA fields of the hippocampus and to the dentate gyrus; (4) layer $\mathrm{V}$ thickness as an account of the main output layer of the EC; (5) combined thickness of layers V and VI as a more complete EC output. Figures 1C,D show a microphotograph of the GA with representation of the distances, as well as its schematic representation. The results for the distances are presented in Table 1.

${ }^{3}$ The name perirhinal cortex is employed as the combination of BA perirhinalis (BA35) and area ectorhinalis (BA36).

${ }^{4}$ The name posterior parahippocampal cortex refers to the posterior part of the PHG, caudal to both entorhinal and perirhinal cortices. This cortical strip was included as part of perirhinal cortex by Brodmann, although it was identified as areas TH and TF by von Economo and Koskinas (1925), as well as in Bailey and von Bonin (1951).

TABLE 1 | Values of the thickness of the EC subfield $E_{M I}$

\begin{tabular}{lcccccc}
\hline Cases & Age & \multicolumn{5}{c}{ Layers } \\
\cline { 3 - 6 } & & I-VI & I-II & I-III & $\mathbf{V}$ & V-VI \\
\hline Case 1 & 71 & 2.8 & 0.7 & 1.5 & 0.3 & 1.2 \\
Case 2 & 58 & 2.3 & 0.5 & 1.2 & 0.4 & 0.8 \\
Case 3 & 78 & 3.2 & 0.4 & 1.3 & 0.3 & 1.2 \\
Case 4 & 82 & 2.0 & 0.6 & 0.8 & 0.3 & 0.8 \\
Case 5 & 83 & 3.0 & 0.5 & 1.5 & 0.4 & 0.9 \\
Case 6 & 59 & 2.6 & 0.5 & 1.2 & 0.5 & 1.1 \\
Case 7 & 90 & 3.0 & 0.6 & 1.5 & 0.5 & 1.2 \\
Case 8 & 61 & 2.5 & 0.6 & 1.3 & 0.5 & 1.0 \\
Case 9 & 83 & 2.3 & 0.5 & 1.3 & 0.4 & 0.9 \\
Case 10 & 75 & 2.2 & 0.4 & 1.2 & 0.3 & 0.8 \\
& Mean & 2.59 & 0.52 & 1.30 & 0.40 & 1.00 \\
& SD & 0.39 & 0.87 & 0.30 & 0.09 & 0.15
\end{tabular}


In order to complete the measurement of the GA, twodimensional maps were constructed and measured with a planimetric program as described previously (Insausti et al., 1998b). In this study, the unfolding corresponds to the middle of the EC, either through lamina dissecans or the interval between layers III and V when the lamina dissecans is absent.

Finally, a total of 10 control subjects MRI from the Radiology Service of the Albacete University Hospital were assessed. Distances from the temporal pole to the limen insulae, the beginning of the hippocampus (subiculum), and the distance between the intrarhinal sulcus and the Gyrus intralimbicus was also calculated as an indirect estimation of the GA extent, calculated from the difference of the two distances alluded to above. The radiological parameters have been reported previously (Delgado-Gonzalez et al., 2015).

\section{RESULTS}

\section{Extent and Limits of the Gyrus ambiens}

The term GA may be derived from its positions facing the ambient cistern (cisterna ambiens), as a descriptive term (latin, ambiens, something that surrounds) that is one of the cerebrospinal fluid spaces in the brain, surrounding the upper part of the mesencephalon, vessels, and nerves (Figures 1A,B).

In our series, the GA is present in all cases medial to the PHG. Two sulci, one dorsal and one ventral, demarcate the GA in the upper, medial part of the MTL. The sulcus located more dorsally is the sulcus semianularis (Figures 1A,B). This sulcus is located at the rostromedial part of the external surface of the amygdaloid complex [cortical part, which is considered as peripaleocortex (Stephan and Andy, 1970)]. Dorsal to the sulcus semianularis lies the periamygdaloid cortex and other medial amygdaloid nuclei; ventral to it lies the GA, so that it can be considered as the boundary between the GA and periamygdaloid cortex. This was a constant feature in our series, although in some cases the periamygdaloid cortex straddled over the sulcus semianularis for a few hundred microns.

The GA is limited ventrally by the intrarhinal sulcus in all our cases (Figure 1B), although in some cases it was very shallow and inconspicuous. This small sulcus runs approximately in the most medial one-third of the distance between the sulcus semianularis and the collateral sulcus. The GA is coincident with the point at which, in a series of coronal sections, the PHG reaches its maximal breadth. At this midpoint of the PHG, the medial shoulder of the collateral sulcus forms the ventral limit of the PHG, while its lateral bank and shoulder belongs to the fusiform gyrus (Gyrus fusiformis), also known as lateral occipitotemporal gyrus (Gyrus occipitotemporalis lateralis) (Nieuwenhuys et al., 2008).

In our series of temporal lobes, the intrarhinal sulcus starts at approximately $9 \mathrm{~mm}$ behind the frontotemporal junction (limen insulae). At this point, the GA begins to be visible on the anterior part of the PHG. The intrarhinal sulcus extends longitudinally for several millimeters $(7-10 \mathrm{~mm})$, although we have observed its shape to vary from a small dimple to a marked depression. Sometimes, a secondary additional sulcus could be appreciated on the surface of the PHG. Moreover, in our series of coronal sections, the end of the intrarhinal sulcus coincided with the start of the hippocampal fissure (fissura hippocampalis) (Amaral and Insausti, 1990; Insausti and Amaral, 2012). In most cases, the intrarhinal sulcus extends as far back as the GA, which corresponds to the level of the hippocampal head. A great symmetry in length of the intrarhinal sulcus between left and right hemispheres was found in our sample of MRI cases $(n=10)^{5}$. Dorsal to the GA, the GS continues with the GU, which corresponds to the amygdalohippocampal area and ends as the hippocampal amygdaloid transitional area (HATA of Rosene and Van Hoesen, 1987; Ding and Van Hoesen, 2015).

The pattern of appearance of the intrarhinal sulcus and the GA above described is the most common in our series of brains, regardless of age. Other variations in the morphology of the GA depend on the presence of other smaller indentations at the surface of the PHG.

\section{Cytoarchitectonics of the Gyrus ambiens Cortex}

We present the topological and cytoarchitectonic features of the cortex of the GA, and its relationship with the cortex of the remainder of the PHG at this level.

Most of the PHG cortex is occupied by an intervening type of cortex, the periallocortex, located between the allocortical fields of the hippocampus, subiculum (three layers), and proisocortex (six layers); the latter also known as mesocortex in the current neuroanatomical nomenclature (cortex of five or six layers, with incomplete lamination scheme). It is the EC, along with the presubiculum and parasubiculum, that form the periallocortex of the PHG (Braak, 1980; Insausti et al., 2017). The basic laminar structure of the EC is of six layers and, although they are also named as layers I-VI, they do not correspond to the layers found in the isocortex (neocortex). The EC presents gradual variation along the anterior-posterior and medial-lateral axes, which justifies the separation of up to eight subfields, in which the transition of one EC subfield to another is gradual rather than sharp (Insausti et al., 1995).

According to the lamination scheme in terms of number and organization of the cortical layers, we determined in our series that the GA, like the EC, is made up of periallocortex. Besides, the continuation between the GA cortex and the remainder of EC is very noticeable (Figures 3, 4). Rostromedially, the GS cortex can be considered as peripaleocortex; it occupies the extensive region that borders the boundary between the periallocortex of the GA and the peripaleocortex of the GS. In a caudal direction, and once the hippocampal fissure is present, the GA comes to an end, and its location is now taken by the GU, which corresponds to the amygdalo hippocampal area, and further caudally by the hippocampus amygdaloid transitional area (Rosene and Van Hoesen, 1987). Therefore, the GA is limited dorsally by the

\footnotetext{
${ }^{5}$ Measurements of the intrarhinal sulcus were taken from MRI series of images in the coronal plane of both sexes. Distances encompassed from the first slice in which the intrarhinal sulcus appears, as far as the first slice where the hippocampal fissure could be noticed.
} 

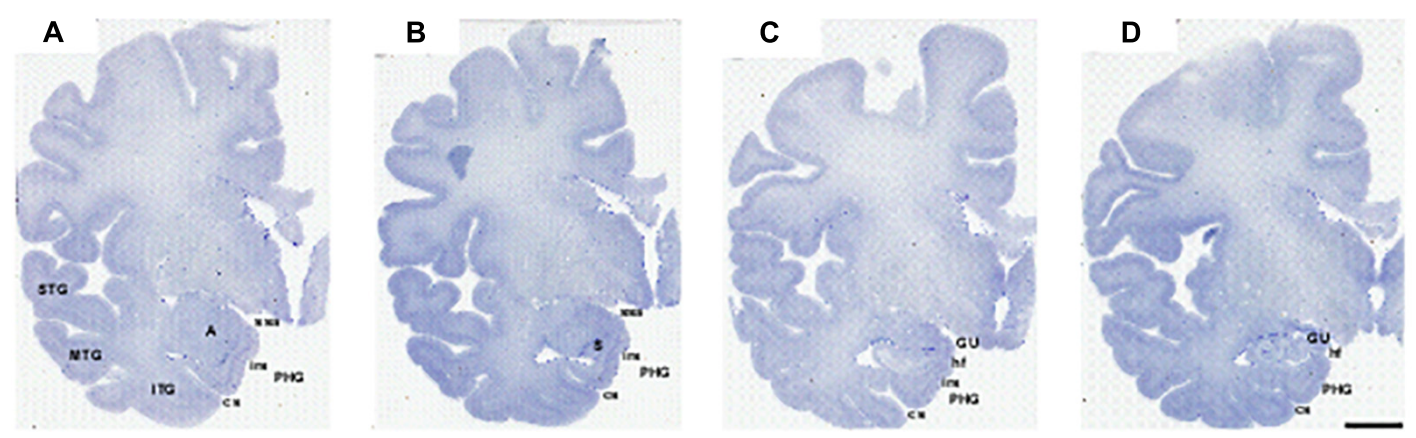

FIGURE 3 | Series of photomicrographs of a whole cerebral hemisphere in coronal sections from rostral (A) to caudal (D), in which the relationship of the GA with the hemisphere and the intrarhinal sulcus are displayed. In panel (A), the rostral level of GA is at the level of the mid amygdala. Panel (B) shows that the maximal extent of the GA is at the level of the commencement of the Subiculum (S). Panel (C) is at the end of the intrarhinal sulcus at the transition with the GU, near the opening of the hippocampal fissure. Note the sulcus semianularis is still evident in panels (A-C). Panel (D) shows the GU past the intrarhinal sulcus at the level of the hippocampus-amygdaloid transitional area (HATA). Abbreviations as in previous figures. Scale bar equals $1 \mathrm{~cm}$.

GS, ventrally by the periallocortex of the EC, rostrally by the anterior portion of the EC, and caudally by the GU. Two of the boundaries (ventral and rostral) correspond to EC while the other two (dorsal and caudal) correspond to parts of the amygdaloid complex.

Our observations indicate that the GA consists of periallocortex, similar to the EC in number and organization of the layers. The main topological features of EC subfields rostrally adjacent to the GA are as follows, according to the nomenclature of Insausti et al. (1995). The anterior pole of the EC shows subfields Entorhinal Olfactory subfield $\left(\mathrm{E}_{\mathrm{O}}\right)$ and Entorhinal Lateral Rostral subfield $\left(\mathrm{E}_{\mathrm{LR}}\right)$, which are the most rostrally located subfields. $\mathrm{E}_{\mathrm{O}}$ resembles the periamygdaloid cortex in terms of appearance (both present a conspicuous layer II organized in clumps) although subfield $\mathrm{E}_{\mathrm{O}}$ shows six layers, as the remainder of the EC, in contrast to the three layers of periamygdaloid cortex. Subfield $\mathrm{E}_{\mathrm{O}}$ abuts laterally subfield $\mathrm{E}_{\mathrm{LR}}$ (for details, see Insausti et al., 1995). Immediately caudal to $E_{O}$ subfield is Entorhinal Rostral subfield $\left(E_{R}\right)$, which also borders the GA anteriorly. Subfield $E_{R}$ presents six layers completely developed, although it lacks lamina dissecans. In a caudal direction the dorsomedial aspect of the EC corresponds to Entorhinal Medial Intermediate subfield $\left(\mathrm{E}_{\mathrm{MI}}\right)$, which is the periallocortex that, along with the incipient angular bundle, makes up the GA.

$\mathrm{E}_{\mathrm{MI}}$ is very noticeable because of specific features. First, $\mathrm{E}_{\mathrm{MI}}$ shows clearly the typical and complete set of layers that characterize the EC. Interestingly, this subfield resembles closely the appearance of the monkey EC, especially at midlevel. Second, it can be accurately distinguished in coronal sections as the medial prominence formed by the GA. In this way, subfield $\mathrm{E}_{\mathrm{MI}}$ covers the majority of the macroscopically GA (Figures 3, 4). In most cases, it is separated from the most ventral part of the periamygdaloid cortex by a conspicuous cell-free space in the medial border of $\mathrm{E}_{\mathrm{MI}}$, which lies slightly ventral to the sulcus semianularis (Figure 4D). The remainder of the EC is in the macroscopically visible PHG. The common features of EC layering are present in all fields, but it is subfield $\mathrm{E}_{\mathrm{MI}}$ that displays them more clearly. Figure 1 shows plainly the stack of layers that characterizes subfield $\mathrm{E}_{\mathrm{MI}}$. Although the cytoarchitectural features of subfield $\mathrm{E}_{\mathrm{MI}}$ have been reported previously (Insausti et al., 1995), briefly, layer I is made up of fibers in continuation with the layers in the periamygdaloid cortex. The pial surface looks smoother relative to other portions of the EC, and, although subfield $\mathrm{E}_{\mathrm{MI}}$ also presents verrucae hippocampi $i^{6}$ their appearance is somewhat flatter. Layer II is narrow and more akin to layer II of subfield $E_{O}$. A thin cell-poor stratum interposes between layers II and III. Layer III is made up of small pyramids, orderly arranged in unicellular columns. A drop in the density in the deep portion of layer III announces lamina dissecans. Layer IV is lamina dissecans, one of the most outstanding features of the human periallocortical regions (Insausti et al., 2017). Lamina dissecans presents a cell-free space, which extends from the border with layer III to the big pyramids that populate the upper portion of layer V. Layer V is made up of three sublayers: Va, which contains densely packed big and dark pyramids; $\mathrm{Vb}$, which displays lower density of pyramids, otherwise similar to those in sublayer Va; and Vc, a cell-poor stratum which runs parallel to lamina dissecans. Layer VI is also multilayered, although not as clearly as layer V. For this reason, this is the only subfield that displays clearly two cell-free bands, lamina dissecans and sublayer Vc, on either side of the dark, big pyramids of layer $\mathrm{V}$, parallel to the convex surface of the GA. While subfield $\mathrm{E}_{\mathrm{I}}$ also presents lamina dissecans and sublayer $\mathrm{Vc}$, it displays a less distinct appearance relative to $\mathrm{E}_{\mathrm{MI}}$. Likewise, subfields $\mathrm{E}_{\mathrm{C}}$ and $\mathrm{E}_{\mathrm{CL}}$, located caudally to $\mathrm{E}_{\mathrm{I}}$, also show a prominent sublayer Vc, although they do not display lamina dissecans (Insausti et al., 1995).

For all of the above, periallocortex of the GA is the same as the cytoarchitectonic type of subfield $\mathrm{E}_{\mathrm{MI}}$, and thence, $\mathrm{EC}$ as one of its subfields (Insausti et al., 1995). There is no other periallocortical field between the GA and the amygdaloid complex, and thereby

\footnotetext{
${ }^{6}$ The term verrucae hippocampi is used as in Klingler (1948) and Simic et al. (2005) to indicate the elevations in the pial surface of otherwise smooth surface of the cortex.
} 

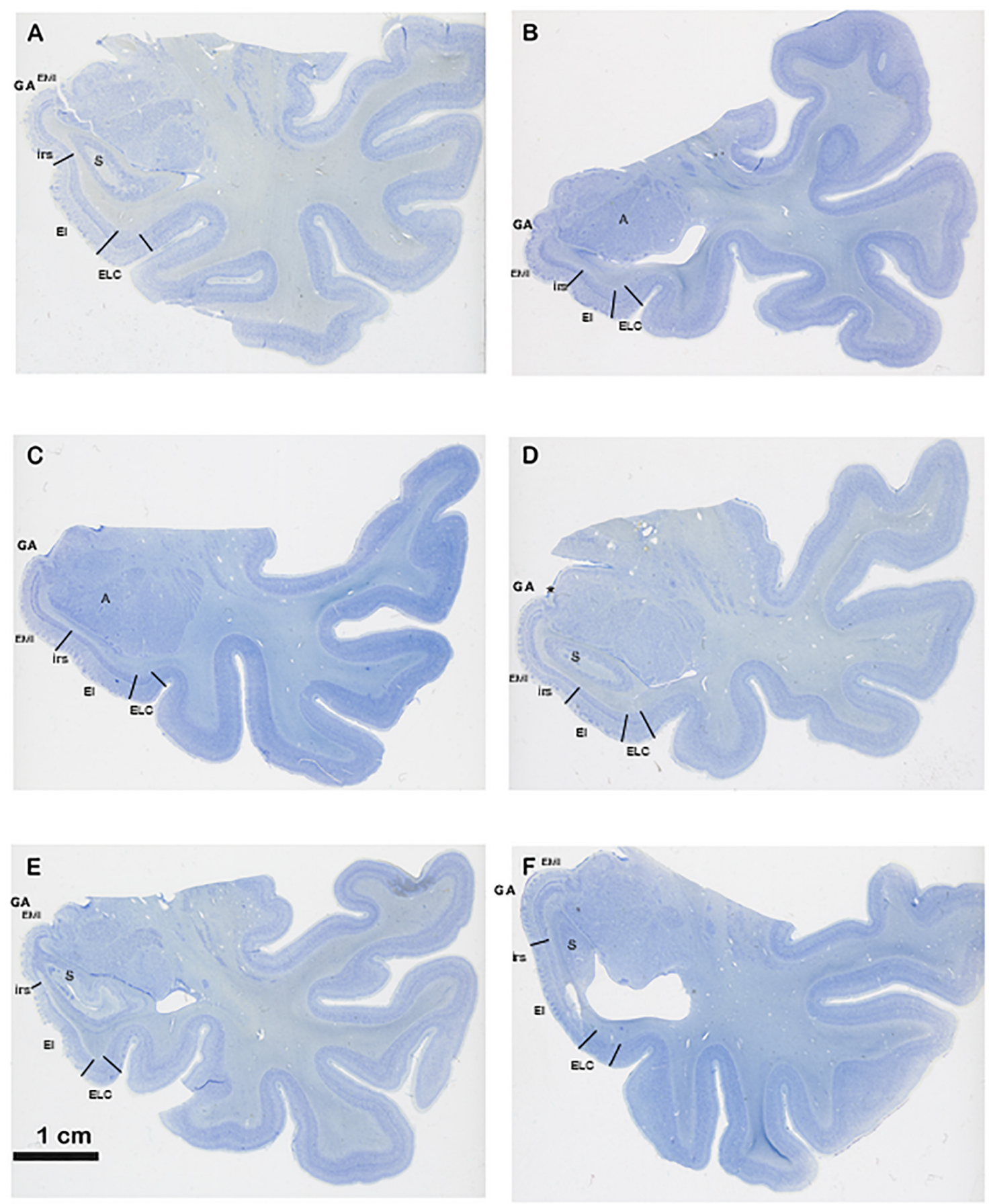

FIGURE 4 | Series of six different cases at the level of the commencement of the Subiculum. The series show different shapes and morphological variability of the GA, in particular differences in depth of the intrarhinal sulcus. Note the sequence from deeper intrarhinal sulcus (A-C) to shallower (D,E), to very shallow (F). Abbreviations as in previous figures: EMI, medial intermediate subfield of the EC; El, intermediate subfield of the EC; ELC, lateral caudal subfield of the EC. Scala bar equals $1 \mathrm{~cm}$.

we must conclude that BA34 is the same as EC subfield $\mathrm{E}_{\mathrm{MI}}$ as defined here, and therefore, a part of BA28, not a different one.

In conclusion, the continuity of the EC along the extent of the GA is given by (a) the ventral continuation of $E_{M I}$ cytoarchitectonic layers with the subfield $\mathrm{E}_{\mathrm{I}}$ in continuation of the EC; (b) the structural difference with the medially adjacent periamygdaloid cortex (peripaleocortex). The rostral part of $\mathrm{E}_{\mathrm{MI}}$ may encroach upon $\mathrm{E}_{\mathrm{O}}$ and $\mathrm{E}_{\mathrm{R}}$, and that completes the GA area. The GA extension is completed by the rostral part of $E_{O}$ and $E_{R}$, as shown in Figure 5. 


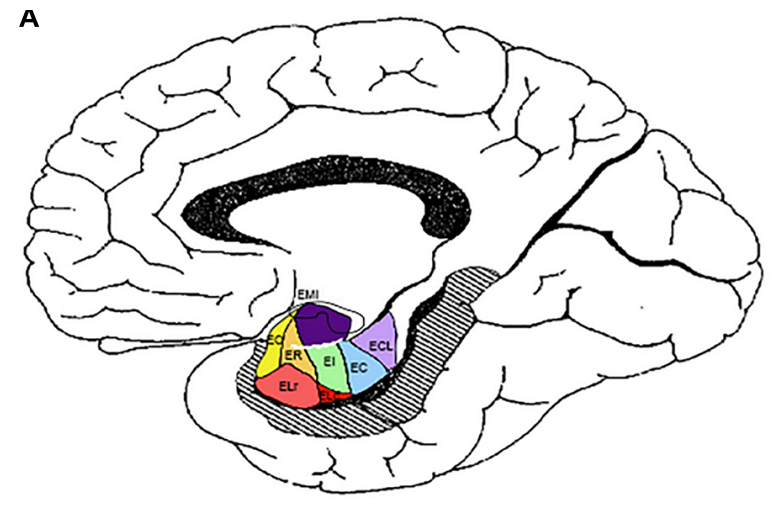

B

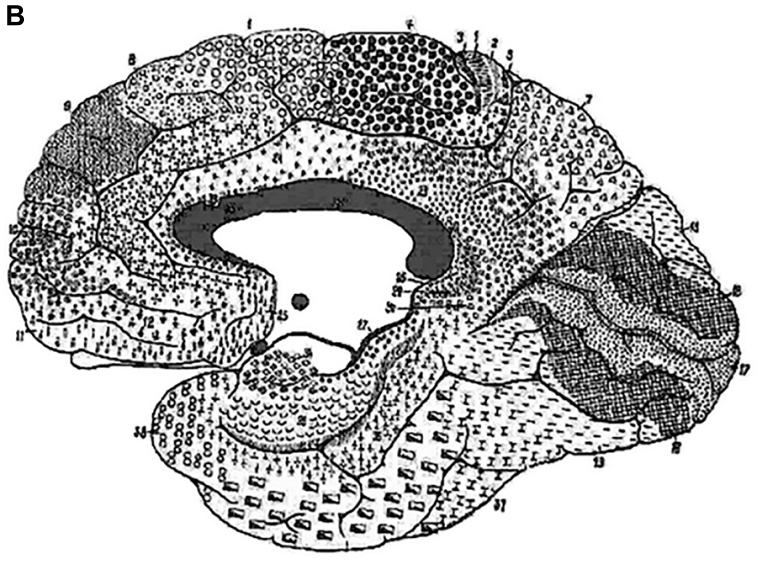

FIGURE 5 | (A) Depiction of the outline of Brodmann's map of the medial surface of the brain. It shows the approximate transformation of EC subfields according to the parcellation of Insausti et al. (1995) into Brodmann's scheme. (B) Brodmann (1909) cytoarchitectonic map. Note the overall correspondence of $\mathrm{EC}$ subfield $\mathrm{E}_{\mathrm{MI}}$ with BA34. Abbreviations as in previous figures: $\mathrm{EC}$, caudal subfield of the EC; ECL, caudal limiting subfield of the EC; ELr, lateral rostral subfield of the EC; EO, olfactory subfield of the EC; ER, rostral subfield of the EC.

\section{Morphometric Parameters of Entorhinal Cortex Subfield $\mathrm{E}_{\mathrm{MI}}$ Cortical Thickness of GA/E $\mathrm{E}_{\mathrm{MI}}$}

In an anterior to posterior direction, the longitudinal extent of the EC is about $2.5 \mathrm{~cm}$. The GA lies at the middle of the EC (Figures 2, 5). We completed this longitudinal distance with the measurement of the EC subfield $E_{M I}$ in Table 1, corresponding to 10 control cases (Age range, 58-90).

The total thickness of EC subfield EMI ranged between 2 and $3.2 \mathrm{~mm}$ [mean 2.59; standard deviation $(\mathrm{SD}) \pm 0.39$ ], and it is relatively constant regardless of the age of the subject. Values for layers I-II of the subfield EMI range from 0.4 to $0.7 \mathrm{~mm}$ (mean $0.52 ; S D \pm 0.87$ ). Layers I-III (EMI upper layers) resulted in values that ranged between 0.8 and $1.5 \mathrm{~mm}$ (mean 1.30; $S D \pm 0.30$ ). Layer $\mathrm{V}$ thickness was the smallest value, as it corresponds to a single layer; values ranged between 0.3 and $0.5 \mathrm{~mm}$ (mean 0.40; $S D \pm 0.09)$. The addition of layers $\mathrm{V}$ and VI varied between 0.8 and $1.2 \mathrm{~mm}$ (mean 1.00; $S D \pm 0.15$ ). Data are presented in Table 1, and show that the range of variability is low, probably due to the sharpness of the limits among layers in this EC subfield.

\section{Two-Dimensional Reconstruction Measurements of $\mathrm{E}_{\mathrm{MI}}$}

Two-dimensional reconstructions allow the measurement of the extent of any cortical area. EC has been unfolded taking the middle of the EC thickness as the unfolding line. Subfield $\mathrm{E}_{\mathrm{MI}}$ extent was unfolded, and the values expressed as percentage of the total EC unfolded surface. Data from a representative number of cases are shown in Table 2. Age ranged from 15 to 110 years to offer a glimpse of the complete lifespan, excluding childhood. All measurements are expressed in $\mathrm{mm}^{2}$ as absolute value, also the value of $\mathrm{E}_{\mathrm{MI}}$ extent, which is also shown as a percentage of the total EC surface.

The EC total surface ranged from 350 to $197 \mathrm{~mm}^{2}$. Values under $200 \mathrm{~mm}^{2}$ corresponded to the two oldest representative cases, 91 and 110 years, respectively $\left(197.3\right.$ and $196.0 \mathrm{~mm}^{2}$ ). Interestingly, in those two old cases, the values of $\mathrm{E}_{\mathrm{MI}}$ were in the normal range. Values of $\mathrm{E}_{\mathrm{MI}}$ extent ranged from 15.0 to $5.0 \mathrm{~mm}^{2}$. Therefore, the percentage of the EC total surface ranged between 1.5 and $6.3 \%$. It is noteworthy to point that the oldest case in our

TABLE 2 | Values of the areal extent of subfield $E_{M I}$.

\begin{tabular}{|c|c|c|c|c|}
\hline Cases & Age & $\mathrm{EC}\left(\mathrm{mm}^{2}\right)$ & $\mathrm{E}_{\mathrm{MI}}\left(\mathrm{mm}^{2}\right)$ & $\%$ \\
\hline Case 1 & 15 & 244.7 & 14.5 & 5.9 \\
\hline Case 2 & 22 & 213.5 & 12.0 & 5.6 \\
\hline Case 3 & 32 & 312.8 & 13.0 & 4.2 \\
\hline Case 4 & 54 & 297.5 & 5.0 & 1.7 \\
\hline Case 5 & 54 & 350.7 & 15.0 & 4.3 \\
\hline Case 6 & 54 & 345.8 & 9.5 & 2.7 \\
\hline Case 7 & 58 & 331.9 & 8.0 & 2.4 \\
\hline Case 8 & 61 & 340.5 & 6.5 & 1.9 \\
\hline Case 9 & 62 & 207.2 & 8.5 & 4.1 \\
\hline Case 10 & 63 & 260.0 & 12.5 & 4.8 \\
\hline Case 11 & 64 & 315.8 & 7.0 & 2.2 \\
\hline Case 12 & 64 & 302.6 & 6.0 & 2.0 \\
\hline Case 13 & 66 & 336.7 & 12.5 & 3.7 \\
\hline Case 14 & 70 & 341.9 & 5.0 & 1.5 \\
\hline Case 15 & 71 & 254.2 & 13.5 & 5.3 \\
\hline Case 16 & 77 & 268.6 & 6.5 & 2.4 \\
\hline Case 17 & 77 & 256.4 & 8.0 & 3.1 \\
\hline Case 18 & 78 & 351.1 & 7.5 & 2.1 \\
\hline Case 19 & 83 & 197.6 & 12.5 & 6.3 \\
\hline Case 20 & 84 & 335.8 & 6.0 & 1.8 \\
\hline Case 21 & 84 & 217.2 & 5.0 & 2.3 \\
\hline Case 22 & 84 & 309.6 & 9.5 & 3.1 \\
\hline Case 23 & 85 & 211.9 & 5.5 & 2.6 \\
\hline Case 24 & 85 & 269.2 & 8.0 & 3.0 \\
\hline Case 25 & 87 & 211.3 & 5.5 & 2.6 \\
\hline Case 26 & 91 & 197.3 & 7.0 & 3.5 \\
\hline \multirow[t]{3}{*}{ Case 27} & 110 & 196.0 & 8.0 & 4.1 \\
\hline & Mean & 277.0 & 8.8 & 3.3 \\
\hline & $S D$ & 56.0 & 3.2 & \\
\hline
\end{tabular}


series showed a percentage of $4.1 \%$, which is in the high range in percentage of all series.

\section{MRI Appearance of the Gyrus ambiens}

The location and extent of the GA in the MTL was established, and the rostrocaudal dimension determined, as well as reference distances with different landmarks used on former MRI studies (Insausti et al., 1998b; Franko et al., 2014).

The series of coronal sections in MRI included levels at which the GA can be recognized. The main landmark for identification of the GA is at the level where the temporal horn of the lateral ventricle starts, or at the level of the start of the subiculum, slightly caudal to the lateral ventricle starting point. Very often, the sulcus semianularis separating the GA and the GS is visible, signaling the dorsal boundary of the GA. The intrarhinal sulcus is also visible in the PHG, although its depth may be somewhat variable. An example of the radiological appearance of the GA is shown in Figure 6.

We determined various parameters in relation to distance from the temporal pole, limen insulae (frontotemporal junction), start of the subiculum, and the end of the uncus (Gyrus intralimbicus), aiming at establishing the location and rostrocaudal extent of the GA in MRI images of 10 human control cases. Table 3 presents the distances among those landmarks. The distance from the beginning of the temporal pole and the limen insulae was fairly constant, $2.5 \mathrm{~cm}$ as an average. The EC starts about $2 \mathrm{~mm}$ behind the limen insulae. The bulge indicating the GA was considered the start of the intrarhinal sulcus. From that point, the distance to the start of the subiculum gave values between 7.2 and $14.4 \mathrm{~mm}$ (mean $9.36 \mathrm{~mm}$; $S D \pm 2.39$ for the left hemisphere and $9.12 \mathrm{~mm}$; $S D \pm 2.48$ for the right hemisphere). The length between the start of the hippocampal fissure and the end of the hippocampal head in the rostrocaudal axis varied between 21 and $14 \mathrm{~mm}$ (left hemisphere, mean $18.96 \mathrm{~mm}$; $S D \pm 2.39$; right hemisphere, mean $18.48 \mathrm{~mm}$; $S D \pm 3.59)$.

\section{DISCUSSION}

\section{Intrarhinal Sulcus and the GA}

In the present report we show that the ventral limit of EC subfield $\mathrm{E}_{\mathrm{MI}}$ (and therefore of the GA) corresponds topographically to the intrarhinal sulcus. The existence of a sulcus that delineates the ventral limit of the GA is well accepted in the literature, although the terminology employed varies among authors.

The sulci of the MTL surface have been examined by different authors, who have shown the variability of the sulci present in the EC. A detailed study of those EC sulci is reported by Hanke (1997), where he refers as "intrarhinal nick" to the sulcus ventral to the GA. Specifically, he states that "the intrarhinal nick forming the lateral border of the ambient gyrus, corresponds to the impression of the of the anterior petroclinoideal plica of the cerebellar tent, and was lacking in $30.4 \%$ of the cases." This suggests that, at the gross morphological level, the intrarhinal sulcus is present in more than two-thirds of the population, thus making it a rather constant feature of the EC. We noticed
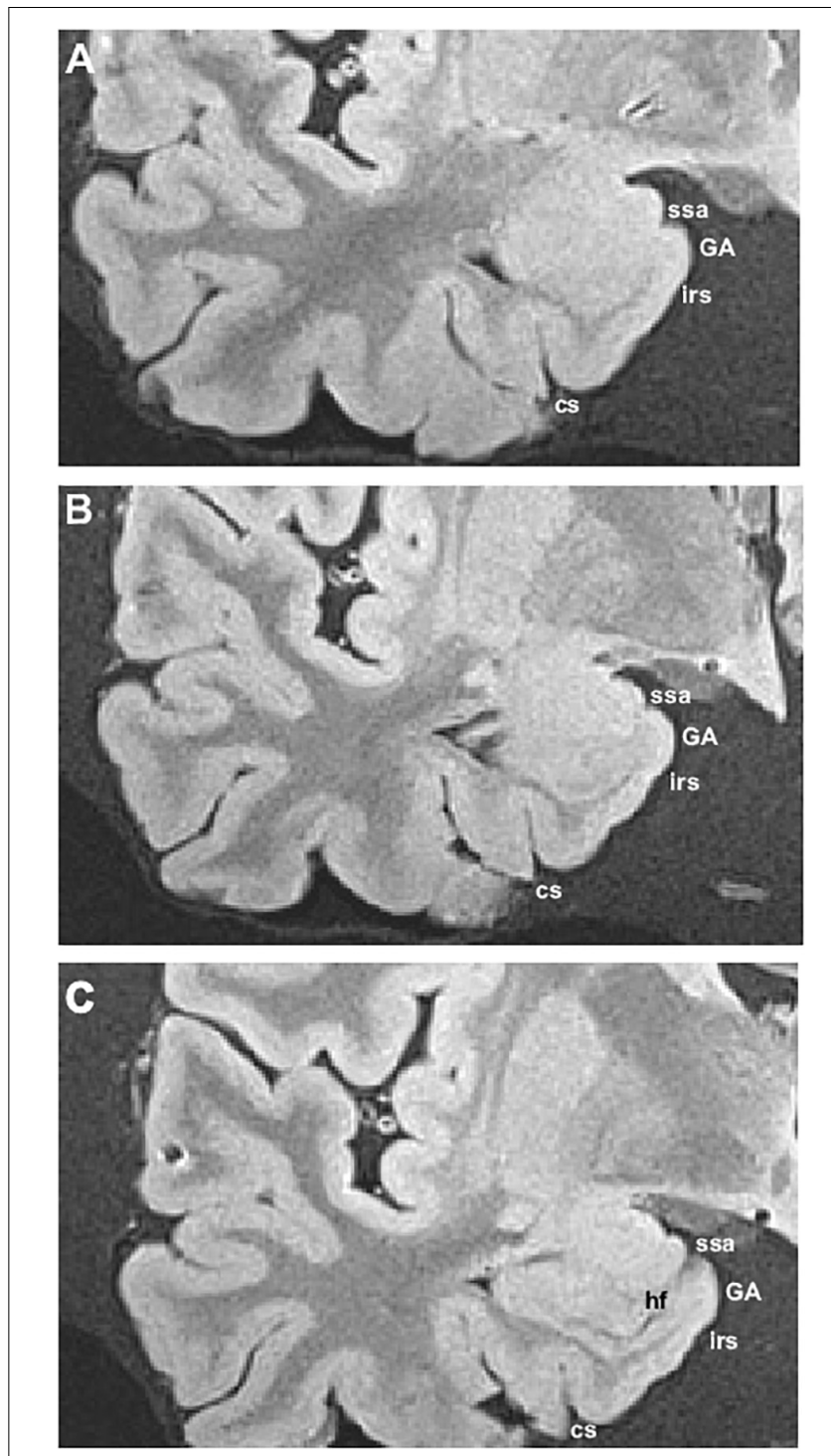

FIGURE 6 | Ex vivo MRI appearance of the GA in coronal sections of three different cases. The boundary of the GA (subfield $\mathrm{E}_{\mathrm{MI}}$ ) was determined by histological examination. Abbreviations as in previous figures.

in our series the constant presence of the intrarhinal sulcus, albeit it was sometimes shallow and not clearly noticeable unless one is aware of the ventral limit of the GA. The presence or absence equally on both sides of the brain suggests that there is no interhemispheric asymmetry (Hanke, 1997). We also found a great hemispheric symmetry of the intrarhinal sulcus in our series of cases. The depth of the intrarhinal sulcus has been associated with the degree of "brain swelling" (Heinsen et al., 1996). While we do not have specific data about brain swelling in the neuropathological report of our cases, it seems unlikely that this condition of the brain is responsible for the appearance of the intrarhinal sulcus.

Other interpretations of the EC sulci in the literature have been proposed (Duvernoy, 2005; Ding and Van Hoesen, 2015), 
TABLE 3 | Length values among MTL landmarks in relation to the GA.

\begin{tabular}{|c|c|c|c|c|c|c|}
\hline \multirow[t]{2}{*}{ Cases } & \multicolumn{2}{|c|}{ Temporal pole - limen insulae } & \multicolumn{2}{|c|}{ irs-subiculum } & \multicolumn{2}{|c|}{ irs-Gyrus intralimbicus } \\
\hline & Left hemisphere & Right hemisphere & Left hemisphere & Right hemisphere & Left hemisphere & Right hemisphere \\
\hline Case 1 & 24.0 & 24.0 & 9.6 & 7.2 & 19.2 & 19.2 \\
\hline Case 2 & 26.4 & 24.0 & 9.6 & 9.6 & 19.2 & 16.8 \\
\hline Case 3 & 21.6 & 24.0 & 12.0 & 12.0 & 21.6 & 19.2 \\
\hline Case 4 & 21.6 & 21.6 & 7.2 & 7.2 & 16.8 & 14.4 \\
\hline Case 5 & 24.0 & 21.6 & 7.2 & 9.6 & 16.8 & 21.6 \\
\hline Case 6 & 26.4 & 26.4 & 7.2 & 7.2 & 16.8 & 16.8 \\
\hline Case 7 & 26.4 & 24.0 & 9.6 & 9.6 & 19.2 & 19.2 \\
\hline Case 8 & 24.0 & 21.6 & 7.2 & 7.2 & 16.8 & 16.8 \\
\hline Case 9 & 24.0 & 24.0 & 9.6 & 7.2 & 19.2 & 14.4 \\
\hline Case 10 & 38.4 & 36.0 & 14.4 & 14.4 & 24.0 & 26.4 \\
\hline Mean & 25.68 & 24.72 & 9.36 & 9.12 & 18.96 & 18.48 \\
\hline$S D$ & 4.81 & 4.24 & 2.39 & 2.48 & 2.39 & 3.59 \\
\hline
\end{tabular}

irs, intrarhinal sulcus.

in particular as an imprint of the free edge of the cerebellar tentorium. However, such imprint would probably interfere with the vascular supply of the EC. This fact, plus the almost constant presence of the intrarhinal sulcus, lead us to conclude that it is a sulcus that forms the ventral boundary of the GA, and thence of the EC subfield $\mathrm{E}_{\mathrm{MI}}$, rather than an imprint of the cerebellar tentorium on the EC surface. The name of intrarhinal sulcus is justified as it lies entirely within the extent of the EC.

\section{The GA Is Cytoarchitectonically EC Subfield $E_{M I}$}

Our study shows that the GA is an EC subfield ( $E_{M I}$ ) which, very likely, coincides with BA34 (Brodmann, 1909). Brodmann named area 34 as "dorsal EC," thus acknowledging that the EC and area 34 share common features. Although Brodmann does not provide a full cytoarchitectonic description of neither area 34 nor area 28 in his 1909 book, he depicts both area 34 and area 28 in great topographical detail, and specifically he states that both areas are separated by the "inferior rhinal sulcus of Retzius," which corresponds to the intrarhinal sulcus. It is unclear why Brodmann separates area 34 as distinct of area 28 , at the same time that he calls it "dorsal EC," instead simply EC. It could be speculated that, taking into consideration a similar lamination between subfield $\mathrm{E}_{\mathrm{MI}}$ and the nonhuman primate EC, Brodmann identified area 34 as a distinct area bases on the similitude with the nonhuman primate $\mathrm{EC}^{7}$.

\section{MRI Identification of the Rostromedial Part of the EC}

The MRI scans used for clinical or experimental studies do not allow the segmentation of specific subfields of the EC. For example, subfield $\mathrm{E}_{\mathrm{O}}$ is very difficult to identify in common MRI

\footnotetext{
${ }^{7}$ Brodmann studied first the cortical parcellation in the nonhuman primate brain, and thereafter in the human brain (Lorente de Nó, personal communication), therefore he was familiarized with the nonhuman primate EC.
}

images (Insausti et al., 1998b; Pruessner et al., 2002; Wolk et al., 2017). However, given that the GA can be identified in MRI examinations, and the very good (almost perfect) match between subfield $E_{M I}$ and the GA, $E_{M I}$ could be the first EC subfield identifiable in MRI scans.

\section{Anatomical and Functional Significance}

Subfield $\mathrm{E}_{\mathrm{MI}}$ presents histo- and immunohistochemical peculiarities, that singles it out of other EC subfields. The distribution of parvalbumin-stained neurons is reduced relative to more lateral parts at similar rostro-caudal levels (Braak et al., 1991; Tuñon et al., 1992; Schmidt et al., 1993; Solodkin and Van Hoesen, 1996; Mikkonen et al., 1997). Calbindin and calretinin immunoreactivity stains more heavily the medial part of the EC (Tuñon et al., 1992; Mikkonen et al., 1997), and therefore, it is largely complementary to that of parvalbumin.

Other neurochemical substances in the EC also distinguish rostromedial $\mathrm{EC}$ subfields $\mathrm{E}_{\mathrm{MI}}$ and $\mathrm{E}_{\mathrm{O}}$. $\mathrm{E}_{\mathrm{MI}}$ and adjacent parts of $E_{O}$ present a paucity of tyrosine hydroxylase-immunoreactive fibers relative to more lateral parts of the EC (Akil and Lewis, 1994). The increasingly and gradual decrease of tyrosine hydroxylase fiber density make subfield $\mathrm{E}_{\mathrm{MI}}$ distinguishable from the adjacent $E_{I}$, although the seamless continuation of the layers with subfield $E_{M I}$ support the contention of its being a subfield of EC. The study of the distribution of choline acetyltransferase in the HF shows that $\mathrm{E}_{\mathrm{MI}}$ displays low density of choline acetyltransferase fibers, density that increases in $\mathrm{E}_{\mathrm{I}}$ with perfect continuation of the EC layers. Significantly, the boundary seems to be coincident with the intrarhinal sulcus (De Lacalle et al., 1994).

Experimental studies in nonhuman primates reveal that the organization of the projections between the EC and the dentate gyrus of the hippocampus share a similar pattern in the nonhuman primate (Witter et al., 1989) and rodent HF (Ruth et al., 1982). The anterior portion of the hippocampus (ventral part in the rodent), which in humans corresponds to 
the hippocampal head, receives innervation from rostromedial portions of the EC. The body and tail of the hippocampus (septal or dorsal part in the rodent) are innervated from progressively more lateral and caudal levels of the EC. Cytoarchitectonic studies of the EC in humans show that rostromedial portions of the EC belong to the $\mathrm{E}_{\mathrm{O}}$ and $\mathrm{E}_{\mathrm{MI}}$ subfields of the EC. The likely homology between EC subfield $\mathrm{E}_{\mathrm{O}}$ and the nonhuman primate EC subfield $\mathrm{E}_{\mathrm{O}}$ (Amaral et al., 1987; Insausti et al., 2002) strongly suggests that this subfield would innervate the head of the hippocampus. Likewise, EC subfield $\mathrm{E}_{\mathrm{MI}}$, which is not present in the nonhuman primate (it is the only EC cytoarchitectonic subfield that is present exclusively in humans), would also likely innervate the head of the hippocampus (Insausti, 1993).

Up to date, ex vivo MRI scans and histology offer the best existing correlation between MRI and the extent of the EC (Adler et al., 2018). The correlation between ex-vivo MRI scans of the MTL with the subsequent histological confirmation are useful for localization of MTL structures (Insausti et al., 1998b; Franko et al., 2014; Delgado-Gonzalez et al., 2015; Adler et al., 2018). However, no specific studies on the GA are available. Our results in a small set of cases suggest that the identification of $E_{M I}$ is feasible, and it may be of use in MRI volumetric determinations.

The MRI identification of the GA has functional implications, as topographical differences in the longitudinal axis of the hippocampus are associated with different functional properties (Maguire et al., 2000; Fanselow and Dong, 2010). The identification of an outstanding GA in most subjects would be useful in the determination of EC subfield $E_{M I}$ and partially of $E_{O}$, with the subsequent implications in the volumetric measurements and cortical thickness studies, as, for instance, in Alzheimer disease (Wolk et al., 2017).

\section{REFERENCES}

Adler, D. H., Wisse, L. E. M., Ittyerah, R., Pluta, J. B., Ding, S. L., Xie, L., et al. (2018). Characterizing the human hippocampus in aging and Alzheimer's disease using a computational atlas derived from ex vivo MRI and histology. Proc. Natl. Acad. Sci. U.S.A. 115, 4252-4257. doi: 10.1073/pnas.180109 3115

Aggleton, J. P., and Mishkin, M. (1985). Mamillary-body lesions and visual recognition in monkeys. Exp. Brain Res. 58, 190-197. doi: 10.1007/BF00238967

Akil, M., and Lewis, D. A. (1994). The distribution of tyrosine hydroxylaseimmunoreactive fibers in the human entorhinal cortex. Neuroscience 60, 857874. doi: 10.1016/0306-4522(94)90268-2

Amaral, D. G., and Insausti, R. (1990). "Hippocampal formation," in The Human Nervous System, ed. G. Paxinos (San Diego, CA: Academic Press), 711-755. doi: 10.1016/B978-0-12-547625-6.50026-X

Amaral, D. G., Insausti, R., and Cowan, W. M. (1987). The entorhinal cortex of the monkey: I. Cytoarchitectonic organization. J. Comp. Neurol. 264, 326-355. doi: 10.1002/cne.902640305

Arnold, S. E., Hyman, B. T., Flory, J., Damasio, A. R., and Van Hoesen, G. W. (1991). The topographical and neuroanatomical distribution of neurofibrillary tangles and neuritic plaques in the cerebral cortex of patients with Alzheimer's disease. Cereb. Cortex 1, 103-116. doi: 10.1093/cercor/ 1.1.103

Bailey, P., and von Bonin, G. (1951). The Isocortex of Man. Champaign, IL: University of Illinois Press.

\section{Summary of Findings and Conclusions}

The present study characterizes the location of GA and the type of cortex that overlies it. It thus seems to be justified to conclude that the cortex lining the GA is the EC subfield $\mathrm{E}_{\mathrm{MI}}$, and therefore part of EC. Likewise, BA34 would be identical to EC subfield $\mathrm{E}_{\mathrm{MI}}$. The topographical situation of the GA in the MTL, plus the coincidence with the EC subfield $\mathrm{E}_{\mathrm{MI}}$ brings the opportunity of its accurate determination in MRI explorations.

\section{ETHICS STATEMENT}

Ethical Committee on Clinical Research of the University Hospital of Albacete, on its meeting of January 2015. Brains obtained before 2002 did not require written consent of next to kin. Brains obtained after this date were obtained under the body and brain donor program of the School of Medicine of the University of Castilla-La Mancha.

\section{AUTHOR CONTRIBUTIONS}

RI designed the study and wrote the manuscript. MC-P and RI contributed equally to the manuscript. MU and AR carried out the measurements. AI and MM-L performed the cytoarchitectonic analysis of the cases.

\section{FUNDING}

This research was partially funded by UCLM funds to the Human Neuroanatomy Laboratory, and the National Institutes of Mental Health 1-R01-AG-056014-01.

Blaizot, X., Mansilla, F., Insausti, A. M., Constans, J. M., Salinas-Alaman, A., ProSistiaga, P., et al. (2010). The human parahippocampal region: I. Temporal pole cytoarchitectonic and MRI correlation. Cereb. Cortex 20, 2198-2212. doi: 10.1093/cercor/bhp289

Braak, E., Strotkamp, B., and Braak, H. (1991). Parvalbumin-immunoreactive structures in the hippocampus of the human adult. Cell Tissue Res. 264, 33-48. doi: 10.1007/BF00305720

Braak, H. (1980). Architectonics of the Human Telencephalic Cortex. Berlin: Springer. doi: 10.1007/978-3-642-81522-5

Braak, H., and Braak, E. (1992). The human entorhinal cortex: normal morphology and lamina-specific pathology in various diseases. Neurosci. Res. 15, 6-31. doi: 10.1016/0168-0102(92)90014-4

Brodmann, K. (1909). Vergleichende Lokalisationslehe der Grosshirnrinde. Leipzig: Verlag von Johann Ambrosius Barth.

Cajal, S. R. Y. (1901). Estructura de la corteza olfativa del hombre y mamíferos. Trab. Lab. Invest. Biol. Univ. Madrid 1, 1-132.

Delgado-Gonzalez, J. C., Mansilla-Legorburo, F., Florensa-Vila, J., Insausti, A. M., Vinuela, A., Tunon-Alvarez, T., et al. (2015). Quantitative measurements in the human hippocampus and related areas: correspondence between Ex-Vivo MRI and histological preparations. PLoS One 10:e0130314. doi: 10.1371/journal. pone. 0130314

De Lacalle, S., Lim, C., Sobreviela, T., Mufson, E. J., Hersh, L. B., and Saper, C. B. (1994). Cholinergic innervation in the human hippocampal formation including the entorhinal cortex. J. Comp. Neurol. 345, 321-344. doi: 10.1002/ cne. 903450302 
Ding, S. L. (2013). Comparative anatomy of the prosubiculum, subiculum, presubiculum, postsubiculum, and parasubiculum in human, monkey, and rodent. J. Comp. Neurol. 521, 4145-4162. doi: 10.1002/cne.23416

Ding, S. L., and Van Hoesen, G. W. (2015). Organization and detailed parcellation of human hippocampal head and body regions based on a combined analysis of cyto- and chemoarchitecture. J. Comp. Neurol. 523, 2233-2253. doi: 10.1002/ cne. 23786

Duvernoy, H. M. (2005). The Human Hippocampus, 3rd Edn. Berlin: SpringerVerlag.

Fanselow, M. S., and Dong, H. W. (2010). Are the dorsal and ventral hippocampus functionally distinct structures? Neuron 65, 7-19. doi: 10.1016/j.neuron.2009. 11.031

Franko, E., Insausti, A. M., Artacho-Perula, E., Insausti, R., and Chavoix, C. (2014). Identification of the human medial temporal lobe regions on magnetic resonance images. Hum. Brain Mapp. 35, 248-256. doi: 10.1002/hbm.22170

Garey, L. J. (1994). Brodmann's 'Localisation in the Cerebral Cortex'. Smith-Gordon: London.

Gloor, P. (1997). The Temporal Lobe and Limbic System. New York, NY: Oxford University Press.

Gómez-Isla, T., Price, J. L., McKeel, D. W. Jr., Morris, J. C., Growdon, J. H., and Hyman, B. T. (1996). Profound loss of layer II entorhinal cortex neurons occurs in very mild Alzheimer's disease. J. Neurosci. 16, 4491-4500. doi: 10. 1523/JNEUROSCI.16-14-04491.1996

Hammarberg, C. (1895). Studien uber Klinic und Pathologie der Idiotie nebst Untersuchungen über die normale Aatomie der Hirnrinde. Berling: Akademische Buchdruckerie.

Hanke, J. (1997). Sulcal pattern of the anterior parahippocampal gyrus in the human adult. Ann. Anat. 179, 335-339. doi: 10.1016/S0940-9602(97)80071-4

Heckers, S., Heinsen, H., Heinsen, Y., and Beckmann, H. (1990). Morphometry of the parahippocampal gyrus in schizophrenics and controls. Some anatomical considerations. J. Neural Transm. Gen. Sect. 80, 151-155. doi: 10.1007/ BF01257080

Heinsen, H., Gossmann, E., Rub, U., Eisenmenger, W., Bauer, M., Ulmar, G., et al. (1996). Variability in the human entorhinal region may confound neuropsychiatric diagnoses. Acta Anat. 157, 226-237. doi: 10.1159/000147885

Huntgeburth, S. C., and Petrides, M. (2012). Morphological patterns of the collateral sulcus in the human brain. Eur. J. Neurosci. 35, 1295-1311. doi: 10.1111/j.1460-9568.2012.08031.x

Iglesias, J. E., Van Leemput, K., Augustinack, J., Insausti, R., Fischl, B., Reuter, M., et al. (2016). Bayesian longitudinal segmentation of hippocampal substructures in brain MRI using subject-specific atlases. Neuroimage 141, 542-555. doi: 10.1016/j.neuroimage.2016.07.020

Insausti, A. M. (1992). Estudio Cito y Mieloarquitectónico de la Circunvolución Parahipocámpica Posterior del Hombre y sus Cambios en la Senescencia Normal $y$ en la Enfermedad de Alzheimer. Ph.D. thesis, Universidad de Navarra, Pamplona.

Insausti, R. (1993). Comparative anatomy of the entorhinal cortex and hippocampus in mammals. Hippocampus 3 Spec No, 19-26.

Insausti, R., and Amaral, D. G. (2008). Entorhinal cortex of the monkey: IV. Topographical and laminar organization of cortical afferents. J. Comp. Neurol. 509, 608-641. doi: 10.1002/cne.21753

Insausti, R., and Amaral, D. G. (2012). "Hippocampal formation," in The Human Nervous System, 3rd Edn, eds J. K. Mai and G. Paxinos (Amsterdam: Elsevier), 896-942. doi: 10.1016/B978-0-12-374236-0.10024-0

Insausti, R., Insausti, A. M., Sobreviela, M. T., Salinas, A., and MartinezPenuela, J. M. (1998a). Human medial temporal lobe in aging: anatomical basis of memory preservation. Microsc. Res. Tech. $43,8-15$.

Insausti, R., Juottonen, K., Soininen, H., Insausti, A. M., Partanen, K., Vainio, P., et al. (1998b). MR volumetric analysis of the human entorhinal, perirhinal, and temporopolar cortices. AJNR Am. J. Neuroradiol. 19, 659-671.

Insausti, R., Marcos, P., Arroyo-Jimenez, M. M., Blaizot, X., and MartinezMarcos, A. (2002). Comparative aspects of the olfactory portion of the entorhinal cortex and its projection to the hippocampus in rodents, nonhuman primates, and the human brain. Brain Res. Bull. 57, 557-560. doi: 10.1016/ S0361-9230(01)00684-0

Insausti, R., Munoz-Lopez, M., Insausti, A. M., and Artacho-Perula, E. (2017). The human periallocortex: layer pattern in presubiculum, parasubiculum and entorhinal cortex. A Review. Front. Neuroanat. 11:84. doi: 10.3389/fnana.2017. 00084

Insausti, R., Tunon, T., Sobreviela, T., Insausti, A. M., and Gonzalo, L. M. (1995). The human entorhinal cortex: a cytoarchitectonic analysis. J. Comp. Neurol. 355, 171-198. doi: 10.1002/cne.903550203

Juottonen, K., Laakso, M. P., Insausti, R., Lehtovirta, M., Pitkanen, A., Partanen, K., et al. (1998). Volumes of the entorhinal and perirhinal cortices in Alzheimer's disease. Neurobiol. Aging 19, 15-22. doi: 10.1016/S0197-4580(98) 00007-4

Khan, U. A., Liu, L., Provenzano, F. A., Bereman, D. E., Profaci, C. P., Sloan, R., et al. (2014). Molecular drivers and cortical spread of lateral entorhinal cortex dysfunction in preclinical Alzheimer's disease. Nat. Neurosci. 17, 304-311. doi: $10.1038 / \mathrm{nn} .3606$

Klingler, J. (1948). Die makroskopische anatomie der ammonsformation. Denkschr. Schweiz. Naturforsch. Ges. 78, 1-80.

Krimer, L. S., Hyde, T. M., Herman, M. M., and Saunders, R. C. (1997). The entorhinal cortex: an examination of cyto- and myeloarchitectonic organization in humans. Cereb. Cortex 7, 722-731. doi: 10.1093/cercor/ 7.8.722

Lorente de Nó, R. (1933). Studies on the structure of the cerebral cortex. I. The area ofentorhinalis. J. Psychol. Neurol. 45, 381-438.

Maguire, E. A., Gadian, D. G., Johnsrude, I. S., Good, C. D., Ashburner, J., Frackowiak, R. S., et al. (2000). Navigation-related structural change in the hippocampi of taxi drivers. Proc. Natl. Acad. Sci. U.S.A. 97, 4398-4403. doi: 10.1073/pnas.070039597

Mikkonen, M., Soininen, H., and Pitkanen, A. (1997). Distribution of parvalbumin-, calretinin-, and calbindin-D28k-immunoreactive neurons and fibers in the human entorhinal cortex. J. Comp. Neurol. 388, 64-88. doi: 10. 1002/(SICI)1096-9861(19971110)388:1<64::AID-CNE5>3.0.CO;2-M

Mohedano-Moriano, A., Martinez-Marcos, A., Pro-Sistiaga, P., Blaizot, X., ArroyoJimenez, M. M., Marcos, P., et al. (2008). Convergence of unimodal and polymodal sensory input to the entorhinal cortex in the fascicularis monkey. Neuroscience 151, 255-271. doi: 10.1016/j.neuroscience.2007.09.074

Muñoz, M., and Insausti, R. (2005). Cortical efferents of the entorhinal cortex and the adjacent parahippocampal region in the monkey (Macaca fascicularis). Eur. J. Neurosci. 22, 1368-1388. doi: 10.1111/j.1460-9568.2005.04299.x

Nieuwenhuys, R., Broere, C. A., and Cerliani, L. (2015). A new myeloarchitectonic map of the human neocortex based on data from the Vogt-Vogt school. Brain Struct. Funct. 220, 2551-2573. doi: 10.1007/s00429-014-0806-9

Nieuwenhuys, R., Voogd, J., and Van Huijzen, C. (2008). The Human Central Nervous System. Berlin: Springer-Verlag. doi: 10.1007/978-3-540-34686-9

Ono, M., Kubik, S., and Abernathey, C. D. (1990). Atlas of the Cerebral Sulci. Stuttgart: Georg Thieme Verlag.

Pruessner, J. C., Kohler, S., Crane, J., Pruessner, M., Lord, C., Byrne, A., et al. (2002). Volumetry of temporopolar, perirhinal, entorhinal and parahippocampal cortex from high-resolution MR images: considering the variability of the collateral sulcus. Cereb. Cortex 12, 1342-1353. doi: 10.1093/cercor/12.12.1342

Retzius, G. (1896). Das Menschenhirn. Stockholm, PA: Norstedt \& Söner.

Rosene, D. L., and Van Hoesen, G. W. (1987). "The hippocampal formation of the primate brain: a review of some comparative aspects of cytoarchitecture and connections," in Cerebral Cortex, eds E. G. Jones and A. Peters (New York, NY: Plenum), 345-456. doi: 10.1007/978-1-4615-6616-8_9

Ruth, R. E., Collier, T. J., and Routtenberg, A. (1982). Topography between the entorhinal cortex and the dentate septotemporal axis in rats: I. Medial and intermediate entorhinal projecting cells. J. Comp. Neurol. 209, 69-78. doi: 10. 1002/cne.902090107

Salinas, A. (1995). Estructura de la Corteza Perirrinal Humana. Modificaciones con el Envejecimiento y la Enfermedad de Alzheimer. Ph.D. thesis, Universidad de Navarra, Pamplona.

Schmidt, S., Braak, E., and Braak, H. (1993). Parvalbumin-immunoreactive structures of the adult human entorhinal and transentorhinal region. Hippocampus 3, 459-470. doi: 10.1002/hipo.450030407

Simic, G., Bexheti, S., Kelovic, Z., Kos, M., Grbic, K., Hof, P. R., et al. (2005). Hemispheric asymmetry, modular variability and age-related changes in the human entorhinal cortex. Neuroscience 130, 911-925. doi: 10.1016/j. neuroscience.2004.09.040

Solly, S. (1836). The Human Brain, Its Configuration, Structure, Development, and Physiology. London: Longman. 
Solodkin, A., and Van Hoesen, G. W. (1996). Entorhinal cortex modules of the human brain. J. Comp. Neurol. 365, 610-617. doi: 10.1002/(SICI)10969861(19960219)365:4<610::AID-CNE8>3.0.CO;2-7

Squire, L. R., Stark, C. E. L., and Clark, R. E. (2004). The medial temporal lobe. Annu. Rev. Neurosci. 27, 279-306. doi: 10.1146/annurev.neuro.27.070203. 144130

Stephan, H. (1975). Allocortex. Berlin: Springer-Verlag. doi: 10.1007/978-3-64280890-6

Stephan, H., and Andy, O. J. (1970). "The allocortex in primates," in The Primate Brain, eds C. R. Noback and W. Montagna (New York, NY: Appleton-CenturyCrofts).

Suzuki, W. A., and Amaral, D. G. (1994). Topographic organization of the reciprocal connections between the monkey entorhinal cortex and the perirhinal and parahippocampal cortices. J. Neurosci. 14(3 Pt 2), 1856-1877. doi: 10.1523/JNEUROSCI.14-03-01856.1994

Swanson, L. W. (2015). Neuroanatomical Terminology. Oxford: Oxford University Press.

ten Donkelaar, H. J., Kachlik, D., and Tubbs, R. S. (2018). An Illustrated Terminologia Neuroanatomica. Cham: Springer. doi: 10.1007/978-3-31964789-0

Tuñon, T., Insausti, R., Ferrer, I., Sobreviela, T., and Soriano, E. (1992). Parvalbumin and calbindin D-28k in the human entorhinal cortex. An inmunohistochemical study. Brain Res. 589, 24-32. doi: 10.1016/0006-8993(92) 91157-A

von Economo, C., and Koskinas, G. N. (1925). Die Cytoarchitektonik der Hirnrinde des Erwachsenen Menschen: Textband und Atlas mit 112 Mikrophotographischen Tafeln. Vienna: Julius Springer.
Williams, P. L., and Warwick, R. (1980). Gray's Anatomy, 36th Edn. Edinburgh: Churchill Livingston.

Witter, M. P., Van Hoesen, G. W., and Amaral, D. G. (1989). Topographical organization of the entorhinal projection to the dentate gyrus of the monkey. J. Neurosci. 9, 216-228. doi: 10.1523/JNEUROSCI.09-01-00216. 1989

Wolk, D. A., Das, S. R., Mueller, S. G., Weiner, M. W., Yushkevich, P. A., and Alzheimer's Disease Neuroimaging Initiative (2017). Medial temporal lobe subregional morphometry using high resolution MRI in Alzheimer's disease. Neurobiol. Aging 49, 204-213. doi: 10.1016/j.neurobiolaging.2016. 09.011

Yushkevich, P. A., Pluta, J. B., Wang, H., Xie, L., Ding, S. L., Gertje, E. C., et al. (2015). Automated volumetry and regional thickness analysis of hippocampal subfields and medial temporal cortical structures in mild cognitive impairment. Hum. Brain Mapp. 36, 258-287. doi: 10.1002/hbm.22627

Conflict of Interest Statement: The authors declare that the research was conducted in the absence of any commercial or financial relationships that could be construed as a potential conflict of interest.

Copyright (c) 2019 Insausti, Córcoles-Parada, Ubero, Rodado, Insausti and MuñozLópez. This is an open-access article distributed under the terms of the Creative Commons Attribution License (CC BY). The use, distribution or reproduction in other forums is permitted, provided the original author(s) and the copyright owner(s) are credited and that the original publication in this journal is cited, in accordance with accepted academic practice. No use, distribution or reproduction is permitted which does not comply with these terms. 